Article

\title{
The Insertion of Economic Cybernetics Students on the Romanian Labor Market in the Context of Digital Economy and COVID-19 Pandemic
}

\author{
Mihaela Simionescu
}

Citation: Simionescu, M. The Insertion of Economic Cybernetics Students on the Romanian Labor Market in the Context of Digital Economy and COVID-19 Pandemic. Mathematics 2022, 10, 222 https: / /doi.org/10.3390/ math10020222

Academic Editor: David Barilla

Received: 18 December 2021

Accepted: 10 January 2022

Published: 12 January 2022

Publisher's Note: MDPI stays neutral with regard to jurisdictional claims in published maps and institutional affiliations.

Copyright: (C) 2022 by the author. Licensee MDPI, Basel, Switzerland. This article is an open access article distributed under the terms and conditions of the Creative Commons Attribution (CC BY) license (https:// creativecommons.org/licenses/by/ $4.0 /)$.
Institute for Economic Forecasting, Romanian Academy, 50711 Bucharest, Romania; mihaela.simionescu@ipe.ro

\begin{abstract}
The purpose of this paper is to provide evidence of the insertion of Romanian students of economic cybernetics on the labor market by connecting business environment expectations with the goals of a competitive digital economy. The research is organized around three hypotheses to address the issues of both non-employed and employed economic cybernetics students. A rank-ordered probit choice model was estimated to compute the probability that a certain skill requires improvement. The empirical results showed that the COVID-19 pandemic stimulated more cybernetics students to get a job in this period. Moreover, these students present the necessary level of digital skills to be employed, but other skills need improvement: skills of analysis and synthesis, adaptability in handling crisis situations and creativity. This research reveals the lack of working experience as the main cause for rejection after an interview and the students' tendency to overestimate their salary. This study also identified barriers of the insertion on the labor market for these students with digital skills that were not the subject of previous studies. Moreover, the impact of the COVID-19 pandemic on their decision to get a job in this period is assessed and a few recommendations of skills improvements are provided. These results present practical implications for educational policies and the business environment in the context of achieving a competitive European digital economy. The limit of this research is given by the sample representativeness for cybernetics students only for Bucharest, but a future paper will ensure a representative sample at the national level.
\end{abstract}

Keywords: labor market; students; digital skills; business environment; digital economy

JEL Classification: C51; C53; J16; J24

\section{Introduction}

The relationship between universities and the economic and social environment should be focused on the achievement of the good insertion of students and graduates on the labor market. In this context, it is necessary to explain the role of universities in providing a quality education that corresponds to the labor market needs and skills required by employers. The formation of these skills is related to investment in education [1] and sustainable cooperation between academic and business environments. The creation of opportunities for quality employment and the support for entrepreneurship initiatives are conditioned by the quality of education provided by universities. In fact, a highly skilled labor force is a necessity for the future of Europe that established precise goals for a successful digital economy.

Europe aims to become a world leader in innovation in the data-driven economy and related applications. This goal can be achieved by combining high-performance digital infrastructure with high-tech and industry opportunities and an appropriate regulatory framework to build an artificial intelligence ecosystem. In addition to the benefits to society as a whole through better healthcare, transport and public services, this ecosystem also has advantages for the labor market in that it requires highly skilled human capital to develop 
innovative services and goods in those areas where the EU is competitive (high valueadded sectors, cyber security, transport, machinery, agriculture, transport, green economy, healthcare). In this context, greater investment is needed in research, development and innovation, including the development of centers of excellence in research. However, besides digital skills, the qualified labor force in this field needs also other important skills and competencies.

In this paper, a sample of economic cybernetics students is analyzed to identify skills that need improvement and other difficulties related to their integration into the labor market. The sample used in this research is representative of economic cybernetics students from Bucharest, the capital of Romania. Even if the representativeness is not ensured at the national level, this paper comes up with relevant results for the connection between the academic environment and social and economic environment to achieve the EU target for a successful digital economy.

Considering this background, this research is organized around three hypotheses to address the issues of both non-employed and employed economic cybernetics students. The research was focused on economic cybernetics students because they have a well-developed background both in economics and cybernetics that allows them to better understand the challenges of the digital economy. The informatics or computer students might be less familiar with economical thinking and the EU targets for the digital economy.

The logical organization of the research on three hypotheses allows us to understand the issues of students based on their status in the labor market. An analysis of the causes of not being already employed is combined with the presentation of reasons for being rejected at interview. Considering the COVID-19 pandemic as beneficial for many students that decided to get employed in this period, we analyzed the skills that need improvement starting from employed students' options and the importance of those skills for their employers. In this case, a rank-ordered probit choice model was estimated to compute the probability that a certain skill requires improvement. As expected, the results confirmed that digital skills are developed enough for the analyzed students, but other skills need significant improvements: creativity, skills of analysis and synthesis and adaptability in handling crisis situations. The recommendations are useful for developing efficient educational policies that ensure the insertion of students and graduates in the digital economy. The main limitation of the study is related to the consideration of a sample of students that is representative only of economic cybernetics students from Bucharest, but, in future research, students from other cities in Romania will be considered.

The empirical results present interest for: (a) policy-makers in education that should develop better policies to connect the higher education with the labor market's requirements, (b) professors teaching to economic cybernetics students that should adapt the educational strategy to the development of specific skills (skills of analysis and synthesis and adaptability in handling crisis situations, creativity), (c) students that should know the challenges of the labor market in their field and should be aware of making more efforts to improve specific skills, (d) managers that could know better the limits and the potential of future employees and (e) researchers that could start from this study to design better research to improve the insertion of cybernetics students into the labor market.

The paper aims to fill the literature gap related to the insertion of students into the labor market during the pandemic. If previous studies suggested that teleworking during the pandemic helped young people with higher education to find easier a job [2-4], none of these studies analyzed a sample of students during the pandemic. Moreover, previous papers were limited to skills of students that should be improved only in the period before the pandemic $[5,6]$. None of the previous studies analyzed the economic cybernetics students. From this point of view, this paper is the first one for Romania and at the international level that provides insights related to the skills of these students with high perspectives for the future digital economy.

Most of the studies focused on the necessity to develop digital skills, but none of them have taken into consideration that students or graduates in this domain should 
improve other necessary skills. In this context, the novelty of this study is related to recommendations for skills improvements in the case of economic cybernetics students from Romania based on the analysis of survey data. Economic cybernetics is focused on the connection between macrosystems and microsystems and it understands the market as a system that could organize and generate itself. The bachelor program 'economic cybernetics' is popular in Romania and it should provide experts with skills in using tools specific to mathematical modeling on economic data, business analytics and modern information and telecommunication technologies. The graduates correspond to the need of the Romanian labor market to grow competitiveness at the micro and macroeconomic levels in the context of the fast development of the digital economy. Economic cybernetics appeared more time ago, while the digital economy is a new concept, but the skills of students in this field help them to adapt to new technological challenges.

After this introduction, the literature review shows the necessity of improving student skills for better insertion into the labor market. Moreover, reasons for considering certain skills in the empirical analysis are provided starting from previous studies and from the targets of the European Commission to achieve a competitive digital economy. The data and methodology description is followed by results presentation, discussion and conclusions.

\section{Literature Review}

The relationship between the academic and business environment is influenced by two paradigms with different actions at the university level: massification [7,8] and globalization [9]. In this context, a continuous adaptation education strategy of universities to the changing needs of society is requested. Besides globalization and massification, universities face issues related to access inequalities, mono industrial areas and depopulation [10]. All these problems that affect students and graduates' transition to work could be overcome through investment in education and good communication and support between academic and business environments. The lack of investment in education and collaboration between universities and the social and economic environment determine significant gaps in the medium and long run.

In Romania, the consolidation of the partnership between companies and the academic environment is required. Specific forms of cooperation in Romania were mentioned by Lazăr et al. [11]: common research projects, discussions related to the content of educational programs to correspond to employers' needs, and the development of better internships.

Only a few studies have given particular attention to the insertion of young students/graduates on the labor market during the pandemic. For example, Anderton et al. noticed that jobs that allow teleworking have played a significant role in supporting hours worked and employment during the COVID-19 pandemic in specific sectors like ITC, while young people with low levels of educations were the most vulnerable persons on the labor market [2]. Jobs in sectors like tourism, transport and trade were the most affected by the pandemic in terms of hours worked. Jobs for economic cybernetics students imply teleworking and the assumption of our study is that the pandemic helped them to get easier a job in the field. Overall, the number of worked hours in the eurozone has declined since the first half of 2020, but it is difficult to appreciate if reallocation across jobs and sectors are necessary.

Nunes et al. analyzed the integration in the Portuguese labor market during the epidemic by employing data at the municipal level and provided useful comparisons based on age, gender, level of education and type of contract [3]. Young people under 35 years old have lower chances to get employed compared to people older than 55 years. A highly educated labor force has more chances to get a job with respect to people with a medium level of education. There are no significant differences between males and females related to their status in the labor market, but a significant increase in the number of temporary contracts has been observed which enhances the asymmetry of the labor market.

Sanchez et al. identified 30\% of the EU employment that correspond to jobs in nonessential sectors that could be performed only at the place of work [4]. These jobs can 
be found in lagging regions and suppose labor force with specific characteristics: young people, less-educated workers and immigrants. From this point of view, people with higher education in economic cybernetics are less exposed to these labor market vulnerabilities generated by the COVID-19 pandemic.

Besides the global context of the pandemic, the gap between graduates' skills and those requested by employers is an important problem even for developed countries. Two aspects might be encountered here: the level of skills is not enough from the employers' perspective or the graduates do not possess a certain type of skill. However, the first form is mostly spread among young graduates, an example being the OECD countries.

The report Education at a glance 2019 suggested significant progress made by OECD countries in terms of people with higher education and their occupation rate: a growth of the number of higher educated young people (25-34 years) and an increase in the occupation rate by 9 percentage points in each case in 2018 compared to 2008 . However, difficulties were encountered regarding the skills of these people and the capacity to respond to labor market needs. Less than $5 \%$ of the graduates in the OECD countries have certified competencies in IT, even if the requests for these competencies is higher [12].

The key path to providing human capital in line with labor market requirements remains in developing long-term skills, competencies and attitudes. The European Qualifications Framework defines several concepts for explaining lifelong learning, which is necessary for fulfilling responsibilities in the workplace:

- learning outcomes materialized in notions known, understood and applied by graduates at the end of the educational process: knowledge, skills and competencies;

- knowledge represented by the information assimilated through the learning process, which can be factual and/or theoretical;

- $\quad$ skills reflected in the ability to apply knowledge to solve various problems, there are practical skills of manual dexterity and cognitive skills based on the use of creative, intuitive and logical thinking;

- competencies embodied in the ability to use knowledge and skills for personal and professional development, but also for performing tasks at work;

- qualifications as results of the process of validating learning outcomes [13].

Good performance at work requires hard skills (organizational and analytical ones) and soft skills (behavioral skills, personal characteristics, creativity), but also threshold skills (minimum requirements required at work) and performance skills that differentiate employees in the successful or unsuccessful performance of work tasks) [14].

The knowledge that students can acquire by completing the courses offered by universities is not enough. Labor market requirements aim to develop other skills than the traditional ones existing in the current education system. In this sense, it is expected that the formation and development of skills and attitudes not only for school but for the whole life of the individual. Lifelong learning for updating skills must support creativity and entrepreneurship in the knowledge-based society. While acknowledging their importance, the current tertiary education system in Romania faces difficulties in developing transversal skills [15]. For example, teamwork refers to transversal skills.

The selection of certain skills and competencies that need improvement in the case of economic cybernetics students is based on theoretical recommendations of previous studies and the European Commission targets of creating a competitive digital economy through suitable digital skills. Creativity is considered a level of digital skills by the European Commission [16] and we selected it as a skill that might need improvement for cybernetics students. On the other hand, we selected digital skills as an overall component since this type of competence is the most important for these students that may choose to work in the ITC sector.

Shively showed that creativity is valuable if it is connected with the curriculum [17]. Moreover, the promotion of creativity in entrepreneurial education has a positive effect on business innovation [18]. These creativity skills present the benefit to be transferable to teamwork, generating value in the company [19]. 
The Institute for the Future proposed six competencies relevant for good integration on the labor market by 2020: the ability to understand the meaning of knowledge, social intelligence, adaptive and innovative thinking, computational thinking, cross-cultural skills, and digital literacy [20]. From this point of view, we selected skills of analysis and synthesis and adaptability in handling crisis situations as relevant to reflect thinking abilities and social intelligence. Computational thinking is already ensured by digital skills. Subia et al. consider analysis and synthesis as essential skills for programming in the case of computer science students [21]. Therefore, these skills are necessary for cybernetics students that want to become programmers. The actual society characterized by job stress requires employees with the capacity to deal with various situations of crisis [5].

By 2030, the OECD anticipates a qualitative transformation of the skills required in the labor market, targeting three groups of skills:

- $\quad$ creating new values for increasing well-being through innovation in areas related to business, jobs, the knowledge society, strategies, techniques and problem-solving ideas; - resolving conflicts at all levels by analyzing the connections between contradictory ideas in the short and long term in order to find practical solutions to problems;

- $\quad$ ability to take responsibility by combining theoretical knowledge with experience and personal, societal and ethical goals [22].

From this point of view, we consider digital skills, teamwork skills, creativity, skills of analysis and synthesis and adaptability in handling crisis situations as relevant for horizon 2030 for the students in our sample. These skills are among the ten ones specified for 2020 by the OECD report based on employers' options. From the analysis of creativity, the skill ranked as the 10th in 2015, it can be easily observed that its position in 2020 is 3rd place, a goal quite difficult to achieve [23]. Problem solving, critical thinking, managing conflicts with people, analysis and decision making remained at the top of employers' preferences. Teamwork ensures the background for the development of other skills: creativity, critical thinking, communication, information sharing [24]. Thomas et al. recommended teamwork during the courses of computer programming to increase the speed and the efficiency of tasks [25]. The main issue that remains is the use of tools for teamwork skills assessment [26].

Few surveys among employers were organized in Romania to identify the types of student skills that require improvement. A survey conducted among employers hiring graduates of Babeș-Bolyai University from Romania highlighted the lack of essential skills. Besides the absence of professional skills, managers observed the tendency of young employees to adopt an inappropriate position towards the work environment, treating the tasks they had to perform with superficiality and lack of involvement. Moreover, graduates overestimated desired salaries, which often do not correspond to their level of knowledge and skills [6].

Another survey conducted in Romania among employers indicates the need to develop software skills, such as teamwork, innovation capacity, flexibility, organizational skills, ability to plan, synthesize information, etc., and to support lifelong learning among graduates [11]. Companies demanded more practical applicability in faculty courses, seminars and laboratories, the facilitation of partnerships with the business environment, as well as proposals for the implementation of new courses. In this context, courses in the field of IT, counseling courses, career guidance and personal development were welcome [6].

Besides skills improvement, the surveys among employers and graduates revealed previous working experience as essential for doing better in job duties. For example, the surveys in Western European countries indicated that $52 \%$ of employers ask for seniority. The importance of seniority is also supported by graduates, 55\% of them gaining work experience before graduation according to the Future of Jobs Report [27].

The European Commission developed action plans for digital education which is also assumed by Romania as the EU member state. There are few relevant competencies for higher education: digitally certified competencies, the existence of a hub for tertiary education, cyber security education, artificial intelligence and strategic planning, development 
programs for digital and entrepreneurial skills [28]. The action plan for digital education proposed for the period 2021-2027 aims to develop digital skills, but also to create a highperformance digital educational ecosystem [29]. The new European Education Area has six dimensions, including tertiary education. One of these dimensions focuses on the qualitative approach suggesting the improvement of required skills for the digital economy.

The labor force mobility and the perspectives of the EU labor market for all the citizens impose the good knowledge of foreign languages. Previous studies highlighted the necessity of knowing a foreign language to increase employability in the EU labor market. For example, according to Grasmane and Grasmane (2011), students from the Latvian University of Agriculture should improve their knowledge of foreign languages to enhance their employability prospects in the EU labor market [30]. A study for V4 countries indicated that English and German languages are necessary for the labor force in these countries in order to gain higher salaries abroad [31]. Therefore, in our research, we considered foreign language skills as important for cybernetics students that might be employed abroad or in a multinational company inside the country that requires this type of skill.

Given the required skills for the future global labor market and the necessity to improve particular skills according to Romanian employers' requests, the next section describes data and methodology that are used in the empirical analysis.

\section{Data and Methodology}

The research is based on non-probabilistic sampling as the selection probabilities are unknown. In this case, the sampling uses the volunteering method, because the inclusion of the respondents in the analyzed group is conditioned by their availability to take the survey. As the response is a voluntary one, the estimators are biased and the sample may not be representative of the analyzed population.

In this case, the population is represented by undergraduate students with a bachelor's domain Economic Cybernetics from the University of Bucharest and the Bucharest University of Economic Studies from Romania. An online questionnaire was used to collect data, the conclusions being formulated at a certain level of confidence. The population volume is 1242 students and it is represented by economic cybernetics students from Bucharest (capital of Romania). The sample volume is determined using a qualitative variable indicating one of the two universities.

$$
\begin{aligned}
n=\frac{z^{2} \cdot p(1-p)}{\Delta_{w}^{2}+\frac{z^{2} \cdot p(1-p)}{N}}= & \frac{1.96^{2} \cdot 0.25}{0.05^{2}+\frac{1.962 .025}{1242}}=\frac{0.9604}{0.0025+\frac{0.9604}{1242}}=\frac{0.9604}{0.0025+0.00077}= \\
& =\frac{0.9604}{0.00327} \cong 294 \text { students }
\end{aligned}
$$

$N$-population volume

$p$-mean of the qualitative characteristic in the population

$\Delta_{W}$-maximum permissible error

$z-z$ score (level of significance $=5 \%$ )

Since the population is not homogenous, $p=0.5$, which implies $p(1-p)=0.25$. For $5 \%$ level of significance, $z=1.96 . \Delta_{W}$ is $\pm 5 \%$.

The sample representativeness is checked using the $\mathrm{z}$ test, knowing that 48 students belong to the University of Bucharest and 246 students come from the Bucharest University of Economics. The share of students in the sample $(w)$ from the University of Bucharest is $16.32 \%$, while the share in the population $(p)$ is $15.45 \%$. The test hypotheses are formulated as:

$$
\begin{aligned}
& \mathrm{H}_{0}: w=p \\
& \mathrm{H}_{1}: w \neq p \\
& \quad z_{\text {calculated }}=\frac{w-p}{\sqrt{\frac{p \cdot(1-p)}{n}}}=\frac{0.1632-0.1545}{\sqrt{\frac{0.0238}{294}}}=\frac{0.0087}{\sqrt{0.00008}}=\frac{0.0087}{0.0089}=0.977
\end{aligned}
$$


$\left|z_{\text {calculated }}\right|<1.96$ and the null hypothesis is not rejected at a $5 \%$ level of significance. This implies that the sample is representative of the analyzed population.

The questionnaire is based on demographic questions related to gender, age, type of funding (fee/budget (no fee)), but also questions related to economic characteristics (income, working experience, aspects related to insertion on the labor market). The questionnaire is presented in Appendix A. The aim of this research is to identify difficulties of insertion on the labor market, causes for interview rejection, the content of managers regarding the quality of students' work; $54.68 \%$ of the students in the sample are men and $45.32 \%$ are females. The average age is 21 years; $46.87 \%$ of the students are not employed, while $53.13 \%$ of them are employed.

The unemployed cybernetics students have to indicate the reason for not being employed:

(a) not searching for a job;

(b) a job in the field was not found;

(c) the salary was not enough;

(d) rejection at the interview.

The students were asked to mention the reason for which they were rejected at the interview having the following options:

(a) the theoretical exam was not passed;

(b) lack of practical skills;

(c) lack of working experience;

(d) lack of foreign languages acknowledge;

(e) lack of enough digital skills;

(f) less competent than other candidates.

The employed students were asked to make a hierarchy of the skills that require improvements through educational programs and they expressed the degree of importance assigned by their managers to those skills: digital skills, creativity, skills of analysis and synthesis, teamwork skills, adaptability in handling crisis situations, foreign language skills. In this study, the skills related to the Bologna process were not considered, since we are interested in those skills that are required by Romanian employers. Previous studies for Romanian students have proven that the skills used in this study are the most frequently required by Romanian managers [15,32].

The main limit of the research is given by the use of a sample that is not representative at the national level. However, the conclusions based on this survey may suggest some useful directions in education policy measures to ensure better integration of cybernetics students and graduates.

The lack of work experience is the main difficulty for the entrance on the labor market in the case of cybernetics students, but the COVID-19 pandemic helped them in getting easier a job due to digital skills. However, this type of skill is not enough for a job. Other types of skills should be improved during the faculty. After introducing this background, a few hypotheses are checked using the analyzed sample:

Hypothesis 1 (H1). The lack of work experience is the biggest obstacle to cybernetics students entering the labor market in Romania.

Hypothesis 2 (H2). The cybernetics students worked more during the pandemic in 2020 compared to previous year.

Hypothesis 3 (H3). The digital skills of cybernetics students are developed enough, but other skills need improvement in order to ensure a better integration on the labor market.

For each hypothesis a certain statistical method is applied:

- H1: frequency histogram and item response theory (IRT);

- H2: $t$-Student test; 
- H3: rank-ordered probit choice model

The methodology focusing on the rank order probit model is described more. Let us consider a student $\mathrm{q}(q=\overline{1, Q})$ that expresses a preference in terms of utility to a certain alternative $i: U_{q_{i}}$. The students are asked to offer a full ranking starting from all the alternatives.

$$
\begin{gathered}
U_{q_{i}}=\beta_{q}^{\prime} x_{q_{i}}+\varepsilon_{q_{i}} \\
\beta_{q}=b+\widetilde{\beta}_{q} \\
\widetilde{\beta}_{q} \rightarrow \operatorname{MVN}_{L}(0, \Omega)
\end{gathered}
$$

$x_{q}=\left(x_{q_{1}}, x_{q_{2}}, \ldots, x_{q_{I}}\right)$ matrix $(\mathrm{I} \times \mathrm{H})$

$x_{q_{i}}$-vector of explanatory variables, including intercept $(\mathrm{H} \times 1)$

matrix $\Lambda$

$U_{q}=\left(U_{q_{1}}, U_{q_{2}}, \ldots, U_{q_{I}}\right)$ vector $(\mathrm{I} \times 1)$

$\beta_{q}$-vector of individual-specific effects $(\mathrm{H} \times 1)$

$\widetilde{\beta}_{q}$-follows a multivariate normal distribution of average $b$ and covariance matrix $\Omega$

$\varepsilon_{q}$-vector of errors following a multivariate normal distribution of average 0 and covariance $\Lambda$

The matrix form of Equation (1) is:

$$
\begin{gathered}
U_{q}=x_{q} b+x_{q} \widetilde{\beta}_{q}+\varepsilon_{q} \\
U_{q} \rightarrow M N V_{Q}\left(V_{q}, \widetilde{\beth}_{q}\right), V_{q}=x_{q} b \text { and } \widetilde{\beth}_{q}=x_{q} \Omega x_{q}^{\prime}+\Lambda
\end{gathered}
$$

The first ranked alternative for a student $\mathrm{q}$ is denoted by $r_{q}^{1}$, the second alternative is $r_{q}^{2}$, while the last one is $r_{q}^{I}$. There are $(I-1)$ inequalities:

$$
U_{q r_{q}^{2}}-U_{q r_{q}^{1}}<0 U_{q r_{q}^{3}}-U_{q r_{q}^{2}}<0 U_{q r_{q}^{I}}-U_{q r_{q}^{I-1}}<0
$$

A contrast matrix $M_{q}[(I-1) \times \mathrm{I}]$ is used to rewrite the previous inequalities [33]. The row is represented by inequality while the column is an alternative. The other elements in the matrix are zero.

$$
u_{q}=M_{q} U_{q}<O_{I-1} u_{q} \rightarrow M V N_{(I-1)}\left(B_{q}, \widetilde{\beth}_{q}\right) B_{q}=M_{q} V_{q} \beth_{q}=M_{q} \widetilde{\beth}_{q} M_{q}^{\prime}
$$

The sample likelihood is given by $\operatorname{Prob}\left(u_{q}<0_{I-1}\right)$. The vector of coefficients is provided by:

$$
\theta=\left(b^{\prime}, \bar{\Omega}^{\prime}, \bar{\Lambda}^{\prime}\right)^{\prime}
$$

$\bar{\Omega}$ - column vector based on stacking of elements in the upper triangle of matrix $\Omega$.

$\bar{\Lambda}$-column vector based on stacking of elements in the upper triangle of matrix $\Omega$.

The evaluation of the likelihood function is based on the maximum approximate composite marginal likelihood [34].

\section{Empirical Results}

Our empirical analysis of the data in a sample will cover the three assumptions following three directions: unemployed students to identify reasons for not having a job and employed students to check if they worked more in 2020 and what improvements in skills are necessary to better do their job. The reasons for unemployment and interview rejection are mentioned in Table 1.

According to Table 1, most of the students rejected at interview claimed the lack of working experience as the main reason for this rejection. Almost half of the unemployed students pretended that they do not search for a job. A quarter of the students without a 
job did not receive a satisfactory wage to get employed, while $20 \%$ of them did not find a job in their field.

Table 1. The reasons for not being employed for cybernetics students.

\begin{tabular}{|c|c|c|c|c|}
\hline $\begin{array}{l}\text { Number of } \\
\text { Each Category }\end{array}$ & $\begin{array}{l}\text { Reason for not } \\
\text { Having a Job }\end{array}$ & Relative Frequency & $\begin{array}{c}\text { Reason for Job } \\
\text { Interview Rejection }\end{array}$ & Relative Frequency \\
\hline 1 & no search for a job & $45 \%$ & lack of working experience & $71.43 \%$ \\
\hline 2 & job interview rejection & $10 \%$ & Better competitors & $14.29 \%$ \\
\hline 3 & Less salary than expected & $25 \%$ & Lack of practical skills & $7.14 \%$ \\
\hline 4 & A job outside the field & $20 \%$ & Lack of digital skills & $7.14 \%$ \\
\hline
\end{tabular}

Source: own calculations.

According to characteristic curves in Figure 1, the probability of not being employed because of a job outside the field presents an ascending tendency, while the lack of working experience diminishes in time after the students succeed in integrating into the labor market. These results indicate that cybernetics students are focused on getting a job in their field in the long-run and the lack of working experience is not a barrier anymore after they get a first job. Therefore, $\mathrm{H} 1$ is supported in this case, but in the long-run after the insertion of the labor market, seniority is not a challenge anymore.

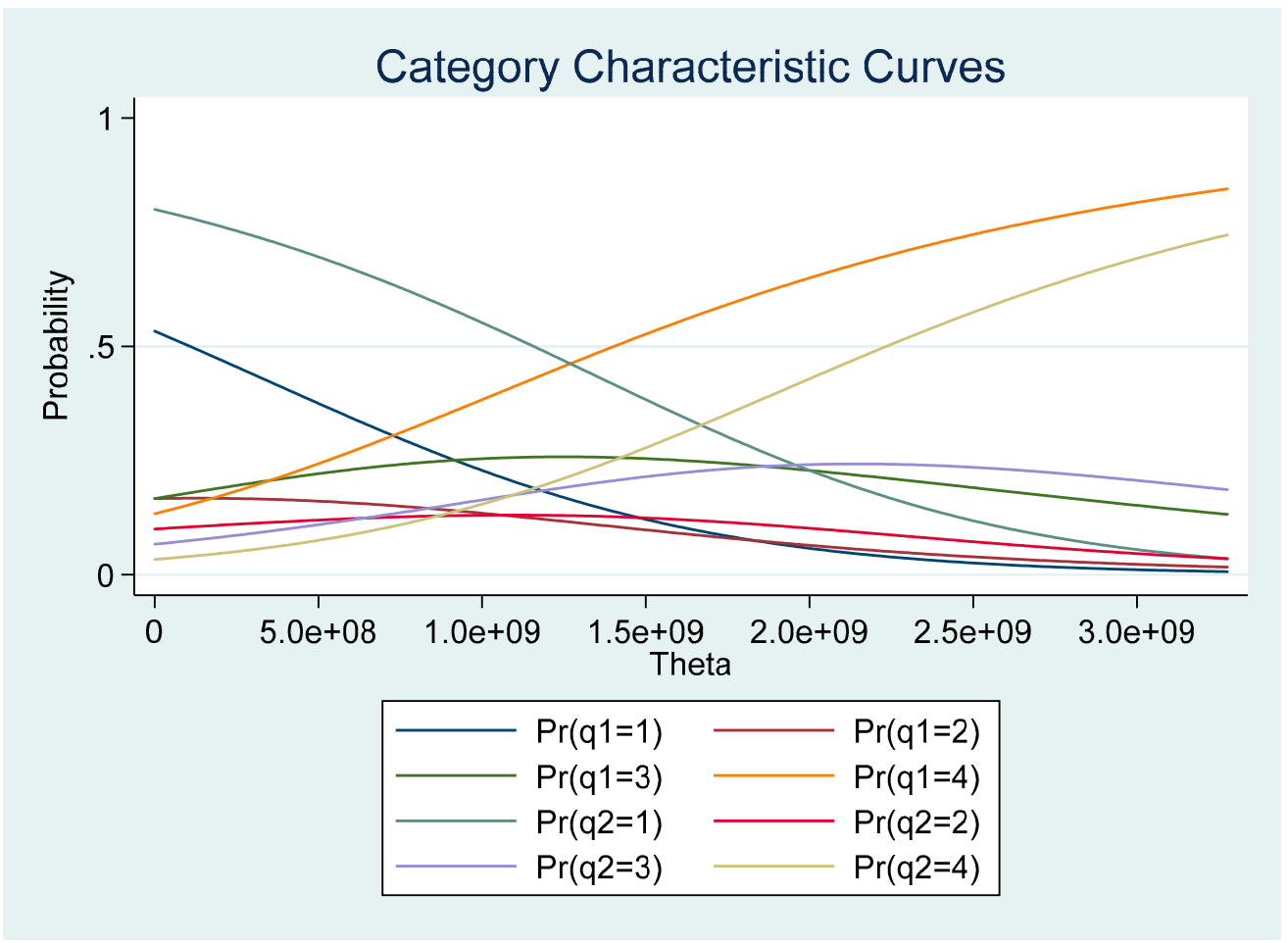

Figure 1. Category characteristic curves.

A t-test in the case of paired two samples for means is applied to check if the number of months worked in 2020 is higher than the number of months in 2019. According to Table 2, the cybernetics students significantly worked more months in 2020, during the pandemic, compared to the previous year, at a $5 \%$ level of significance.

The students in the sample were asked to make a hierarchy regarding the improvements in skills during higher education studies for better integration in the labor market. The importance is ranked from 1 to 6 , where 1 is assigned to the skill that needs the highest improvement. The skills refer to: 


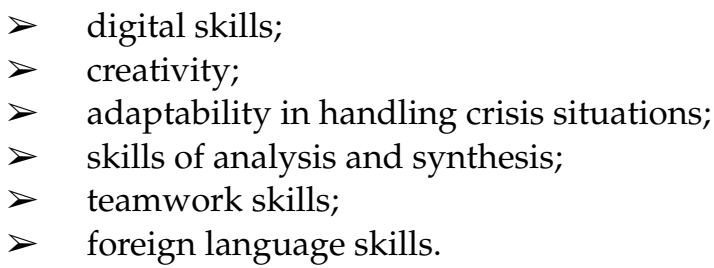

Table 2. Differences between the numbers of months worked in 2019 and in 2020 .

\begin{tabular}{lcc}
\hline \multicolumn{1}{c}{ Indicator } & Months in 2019 & Months in 2020 \\
\hline Mean & 3.833333 & 6.777778 \\
\hline Variance & 16.02941 & 20.88889 \\
\hline $\mathrm{P}(\mathrm{T} \leq \mathrm{t})$ one-tail & 0.00467 & - \\
\hline $\mathrm{t}$ Critical one-tail & 1.739607 & - \\
\hline $\mathrm{P}(\mathrm{T} \leq \mathrm{t})$ two-tail & 0.009341 & - \\
\hline $\mathrm{t}$ Critical two-tail & 2.109816 & - \\
\hline Source: own calculations. & &
\end{tabular}

The covariates in the model are related to gender and education form (tuition fee/no tuition fee). The opinion of the manager of each student related to the importance of each skill is also required (relevant/less relevant/non-relevant skill). These opinions are collected from students based on their perceptions related to the importance assigned by managers to each skill. However, since the information is not directly collected from managers, these perceptions might be subjective in some cases. The estimations for the rank-ordered probit choice model are presented in Table 3.

The education form is not relevant in explaining the options of the students that chose creativity as the skill requiring the highest improvement. For the other alternatives, gender and education forms are relevant in explaining the options at a $10 \%$ level of significance.

The probabilities of selecting a certain skill as the one requiring the highest improvement for the transition to work are displayed in the next table (Table 4):

Skills of analysis and synthesis have the greatest probability to be considered the ones that require the most consistent improvement (probability of 0.46 ), while the digital skills require less improvement. Adaptability in handling crisis situations and creativity also needs improvement, but to a lower extent.

These results suggest that cybernetics students possess the digital skills required by the labor market, but they encounter difficulties related to critical thinking, adaptability to crisis situations and creativity.

For each option, we are interested in recalculating the probabilities taking into account the importance assigned by managers (Table 5). In this case, 53\% of the employed cybernetics students whose managers consider skills of analysis and synthesis as relevant for their jobs would consider that this type of skill requires the greatest improvement; $34 \%$ of the students whose managers consider relevant for their job the ability to face crisis would assign priority to this skill.

Table 3. The results of rank-ordered probit choice model.

\begin{tabular}{ccc}
\hline Rank & Coefficient & $p$-Value \\
\hline Choices (base alternative: digital competencies) & - & - \\
\hline Importance given by managers & - & - \\
\hline Relevant & 0.217 & 0.000 \\
\hline $\begin{array}{c}\text { Creativity } \\
\text { Female }\end{array}$ & -0.261 & 0.041 \\
\hline No fee & 0.109 & 0.727 \\
\hline
\end{tabular}


Table 3. Cont.

\begin{tabular}{|c|c|c|}
\hline Rank & Coefficient & $p$-Value \\
\hline Constant & -2.432 & 0.000 \\
\hline $\begin{array}{l}\text { Adaptability in handling crisis situations } \\
\text { Female }\end{array}$ & -0.921 & 0.077 \\
\hline No fee & 0.322 & 0.030 \\
\hline Constant & -2.578 & 0.000 \\
\hline $\begin{array}{l}\text { Skills of analysis and synthesis } \\
\text { Female }\end{array}$ & -0.499 & 0.094 \\
\hline No fee & 0.220 & 0.044 \\
\hline Constant & -1.724 & 0.000 \\
\hline $\begin{array}{c}\text { Teamwork skills } \\
\text { Female }\end{array}$ & -0.594 & 0.003 \\
\hline No fee & 0.315 & 0.086 \\
\hline Constant & -0.246 & 0.130 \\
\hline $\begin{array}{l}\text { Foreign language skills } \\
\text { Female }\end{array}$ & -0.642 & 0.000 \\
\hline No fee & 0.214 & 0.016 \\
\hline Constant & 0.235 & 0.101 \\
\hline
\end{tabular}

Source: own calculations in Stata 16.

Table 4. Probabilities that students select a skill as the one that needs the highest improvement.

\begin{tabular}{ccc}
\hline Option & Probability & $p$-Value \\
\hline Digital skills & 0.03 & 0.154 \\
\hline Creativity & 0.11 & 0.000 \\
\hline $\begin{array}{c}\text { Adaptability in handling crisis } \\
\text { situations }\end{array}$ & 0.30 & 0.000 \\
\hline Skills of analysis and synthesis & 0.46 & 0.000 \\
\hline Teamwork skills & 0.04 & 0.049 \\
\hline Foreign language skills & 0.06 & 0.047 \\
\hline
\end{tabular}

Source: own calculations in Stata 16.

Table 5. Probabilities for each skill to require the biggest improvement knowing the importance assigned by managers.

\begin{tabular}{ccc}
\hline Option & Probability & $p$-Value \\
\hline Digital skills & 0.03 & 0.159 \\
\hline Creativity & 0.10 & 0.000 \\
\hline Adaptability in handling crisis situations & 0.34 & 0.000 \\
\hline Skills of analysis and synthesis & 0.53 & 0.000 \\
\hline Teamwork skills & 0.10 & 0.000 \\
\hline Foreign language skills & 0.09 & 0.030 \\
\hline
\end{tabular}

Source: calculations in Stata 16.

\section{Discussion}

Cybernetics students possess the digital skills to integrate into the labor market, but most of the unemployed ones did not search for a job. However, most of them were not motivated by the offered salary, while other ones refused to work in another field. The 
results are in line with the salary expectations for engineering students in the study of Taylor [35] that are much higher than the expectations of students in social sciences. UK students also overestimated their starting wages [36]. The salary expectations are relevant for public policies in higher education, human capital theory and patterns of students' enrolment. In this case, the cybernetics students might overestimate their salaries. In a previous study, Lazăr and Robu showed that the graduates from Babeș-Bolyai University in Romania overestimated their salaries [6].

The economist students also claimed difficulties in finding a job in their field (Deaconu și Trașcă, 2014). The competition for jobs is also important in motivating the human capital to improve the skills and conditions for success at a job interview. The global labor market is characterized by competition that determines salaries [37].

The analysis of the causes of rejection at the interview shows that the biggest obstacle to hiring new graduates with advanced digital skills is the lack of working experience (seniority). Therefore, some students work even during the faculty, but not always in their field of training. The experience requirement is associated with the lack of labor market flexibility, as is the case in Romania. The relatively long seniority of employees is positively associated with employee protection legislation, as Burgess et al. show [38]. Moreover, Boockmann and Steffes showed that labor market institutions are the ones that ensure the extension of working experience and the reduction of mobility [39]. There are previous studies for Romanian students in other fields which showed that the lack of seniority is the major issue for their insertion into the labor market. For example, Naros showed that labor experience is required for students graduating in economic studies in Romania [15]. Deaconu and Rașcă showed that students in economics want to work during their studies to achieve the necessary seniority after their graduation [40].

The seniority problem should be solved as fast as possible given the international context of the COVID-19 pandemic. Progress has been made since cybernetics students worked more during the pandemic compared to the year before, but financial support should be ensured for employers that hire students. Eurofound research showed that the volatility of the business cycle affects seniority requirements [41]. The last global economic crisis has been grown the level of seniority because of the short-term jobs and the COVID-19 pandemic could make the same.

Possible solutions to the working experience issue might be more internships and digital entrepreneurship. Paid internships could be introduced in Romania, following the good practices of developed countries like the Netherlands or Nordic countries. A permanent internship platform should be developed in Romania to ensure the dialogue between students/graduates, universities and employers. The selection of the most suitable company for internship in the case of each student should be preceded by an individual counselor to identify the suitable professional route.

Additional training is necessary for students to improve their entrepreneurial skills. Digital entrepreneurship that intensifies digital knowledge and skills should be supported by universities and mentoring programs, but digital start-ups will require financial instruments that can be provided by governments [42]. The number of faculties or study programs that prepare graduates for the fields required by the digital economy has to increase, while those faculties that do not provide jobs that are competitive in the labor market should adapt their educational offer to the requirements of the digital economy. Besides the creation of new jobs, digital entrepreneurship contributes to the development of human capital that could ensure a competitive EU economy [43].

However, even if students choose to be digital entrepreneurs they should also prove other skills. The necessity of improving the students' skills was also pointed out by Naros, for young economists at their entrance on the Romanian labor market [25]. Moreover, Deaconu and Rașcă indicated that students from the Bucharest University of Economics do not have the necessary competencies to get employed easy and improvements should be made to educational programs [40]. 
Most of the employed students in our sample consider that skills of analysis and synthesis require the greatest improvement. Other skills that should be improved are adaptability in handling crisis situations and creativity. These skills present also high importance for the managers. These results are consistent with the observations in the Future of Jobs report of the World Economic Forum [27]. The most important skills up to 2025 include critical thinking and analysis, flexibility and stress tolerance. A solution to these challenges might be the improvement of educational programs that should avoid the exclusive focus on information provision. The promotion of life-long learning and the objectives of the EU strategy for education should be followed by education staff. More public expenditure for the education sector is needed to ensure training for professors and more education personnel to imply more in the educational activity. Analytical skills are formed through better supervision in writing the bachelor dissertation. Better public financing of higher education in Romania is also a measure promoted by other studies [44] that recommend the model of funding from developed European countries like the UK.

Moreover, the creation of sustainable universities in Romania promoting a high-quality higher education should be based on suitable educational strategies. These sustainable universities should be more connected to labor market requests. The social and environmental responsibility promoted in these universities could contribute to economic growth through innovative activities.

The new understanding of the exposed issue is related to the fact that the COVID-19 pandemic helped the economic cybernetics students to get easier a job due to teleworking. Previous studies highlighted that some sectors that allow teleworking have been favored during the pandemic, but none of these papers focused on students working in a specific sector that encourages this type of work. Moreover, specific skills that should be improved from managers' perspectives are revealed in this study for this specific type of student that already has well-developed digital skills.

\section{Conclusions}

Even if Romania is among the countries with a low level of digital skills, the cybernetics students present the necessary background to respond to the requirements of employers in the ITC sector. However, other types of skills should be improved in their case, even if the COVID-19 pandemic accelerated the digital transformation and help them to better integrate into the Romanian labor market. The online lectures and teleworking during the epidemic might also stimulate students to apply for a job.

This study identified macroeconomic and microeconomic factors the affect the insertion of cybernetics students on the labor market and few recommendations are provided. The Romanian labor market is not flexible yet imposing seniority even to recent graduates and students. In this context, paid internships and digital entrepreneurship should be intensified. Even if the level of digital skills is acceptable for cybernetics students to get a job in this field, other skills need improvement requiring better higher education public funding and improvement in educational programs. Skills of analysis and synthesis require the most consistent improvement, while adaptability in handling crisis situations and creativity should be also better developed. However, continuous training for faculty staff is also necessary to help them in providing better education with more focus on students rather than knowledge that should be transmitted.

This research presents a few limitations from a practical and methodological point of view. The analyzed sample is representative only of economic cybernetics students from Bucharest. In a future study, cybernetics students from other universities in the country should be considered in the sample. Moreover, it is important to make the distinction between economic cybernetics students and informatics students and make a separate analysis regarding the transition from faculty to work. The economic cybernetics students have the advantage of working also in economic fields given their economical background. A comparative study between the skills of economic cybernetics students and informatics students would be also necessary. 
Another limitation of the study is given by the consideration of a few skills that might be improved. In future research, other skills should be included like critical thinking, communication, or research skills. This research is limited to a few options in explaining the rejection at interview and reasons for not having a job. Therefore, students could be asked to write another variant of response if none of the mentioned ones fits their case.

Funding: This research is part of the research plan of the Institute for Economic Forecasting of the Romanian Academy for 2022 with the title: "Unemployment among higher educated young people. Evolutions and particularities in the European Union".

Informed Consent Statement: Informed consent was obtained from all subjects involved in the study.

Data Availability Statement: The data that support the findings of this study are available upon request.

Acknowledgments: This is a non-interventional study (survey), where ethical approval is not required because of national laws. However, the respondents expressed their consent to complete the online questionnaire.

Conflicts of Interest: The author declares no conflict of interest.

\section{Appendix A Questionnaire}

1. Are you currently employed or have you been employed before?
(a) Yes;
(b) No.

2. Number of months worked in 2019: ... . . .

3. Number of months worked in 2020: ... . . .

4. Your seniority in work (in months): ...

5. Seniority in current job (in months):... .

6. What skills do you think should be improved during your studies so that graduates in your field can better meet the requirements of the job? Order these skills/abilities, giving rank 1 to the one that needs the most improvement and rank 6 to the one that needs a little improvement.
(a) Digital skills ........
(b) Creativity .....
(c) Adaptability in handling crisis situations .......
(d) Teamwork skills .....
(e) Skills of analysis and synthesis ......
(f) Foreign language skills .....

(a) 7. How important are the above skills to your manager? (1-less important; 2-indifferent; 3-important)Digital skills ... . . . .

(b) Creativity .....

(c) Adaptability in handling crisis situations .......

(d) Teamwork skills .....

(e) Skills of analysis and synthesis ......

(f) Foreign language skills .....

8. How satisfied is the manager of the company/institution you work at with your level of professional training acquired in faculty?
(a) satisfied;
(b) dissatisfied).

9. Your age (in years): ......

10. Your gender: .........

11. If you are not employed, what is the main reason for not getting hired?
(a) not searching for a job;
(b) a job in the field was not found;
(c) the salary was not enough; 
(d) rejection at the interview.

12. If you were ever rejected at the interview, what was the main cause?

(a) theoretical exam was not passed;

(b) lack of practical skills;

(c) lack of working experience;

(d) lack of foreign languages acknowledge;

(e) lack of enough digital skills;

(f) less competent than other candidates.

13. What skills do you think should be improved during your studies so that graduates in your field can better meet the requirements of the job? Order these skills, giving rank 1 to the one that needs the most improvement and rank 6 to the one that needs a little improvement.

(a) Digital skills ........

(b) Creativity .....

(c) Adaptability in handling crisis situations .......

(d) Teamwork skills .....

(e) Skills of analysis and synthesis ......

(f) Foreign language skills .....

14. Type of funding for your studies:

(a) Fee

(b) budget (no fee)

15. Your monthly income: ......

\section{References}

1. Gauttier, P. Horizontal coherence and the external competences of the European Union. Eur. Law J. 2004, 10, 23-41. [CrossRef]

2. Anderton, R.; Botelho, V.; Consolo, A.; Da Silva, A.D.; Foroni, C.; Mohr, M.; Vivian, L. The impact of the COVID-19 pandemic on the euro area labour market. Econ. Bull. Artic. 2021, 8, 1-15.

3. Nunes, C.; Carvalho, B.P.; dos Santos, J.P.; Peralta, S.; Tavares, J. Failing Young and Temporary Workers: The Impact of COVID-19 on a Dual Labour Market; Mimeo: Lisboa, Portugal, 2021.

4. Sanchez, D.G.; Parra, N.G.; Ozden, C.; Rijkers, B. Which jobs are most vulnerable to COVID-19? What an analysis of the European Union reveals. In What an Analysis of the European Union Reveals (May 11, 2020); World Bank Research and Policy Briefs; World Bank: Washington, DC, USA, 2020; p. 148384.

5. Jalagat, R. Determinants of job stress and its relationship on employee job performance. Am. J. Manag. Sci. Eng. 2017, 2, 1-10. [CrossRef]

6. Lazăr, J.B.; Robu, D. Accelerating the development of learning organizations: Shifting paradigms from current practice to human performance improvement. Theor. Appl. Econ. 2015, 22, 241-256.

7. Jongbloed, B.; Vossensteyn, H. University funding and student funding: International comparisons. Oxf. Rev. Econ. Policy 2016, 32, 576-595. [CrossRef]

8. Okolie, U.C.; Nwajiuba, C.A.; Eneje, B.; Binuomote, M.O.; Ehiobuche, C.; Hack-Polay, D. A critical perspective on industry involvement in higher education learning: Enhancing graduates' knowledge and skills for job creation in Nigeria. Ind. High. Educ. 2021, 35, 61-72. [CrossRef]

9. Dobbins, M.; Kwiek, M. Europeanisation and globalisation in higher education in Central and Eastern Europe: 25 years of changes revisited (1990-2015). Eur. Educ. Res. J. 2017, 16, 519-528. [CrossRef]

10. Ivanova, E. Barriers to the development of SMEs in the Slovak Republic. Oeconomia Copernic. 2017, 8, 255-272. [CrossRef]

11. Lazăr, I.; Mortan, M.; Vereş, V.A.; Lazăr, S.P. Management General; Risoprint: Cluj-Napoca, Romania, 2004.

12. OECD. Education at a Glance 2019. 2019. Available online: https://www.oecd.org/education/higher-education-needs-to-stepup-efforts-to-prepare-students-for-the-future.htm (accessed on 7 October 2021).

13. Mhamed, A.A.S.; Vossensteyn, H.; Kasa, R. Stability, performance and innovation orientation of a higher education funding model in Kazakhstan. Int. J. Educ. Dev. 2021, 81, 102324. [CrossRef]

14. Purwanto, A.; Santoso, P.B.; Siswanto, E.; Hartuti, H.; Setiana, Y.N.; Sudargini, Y.; Fahmi, K. Effect of Hard Skills, Soft Skills, Organizational Learning and Innovation Capability on Islamic University Lecturers' Performance. Int. J. Soc. Manag. Stud. 2021, 2, 14-40.

15. Naros, M.S. Romanian economists and the labour market. Czech J. Soc. Sci. Bus. Econ. 2018, 7, 6-15. [CrossRef]

16. Morris, T.H. Creativity through self-directed learning: Three distinct dimensions of teacher support. Int. J. Lifelong Educ. 2020, 39, 168-178. [CrossRef] 
17. Shively, C.H. Grow Creativity! Learn. Lead. Technol. 2011, 38, 10-15.

18. Gundry, L.K.; Ofstein, L.F.; Kickul, J.R. Seeing around corners: How creativity skills in entrepreneurship education influence innovation in business. Int. J. Manag. Educ. 2014, 12, 529-538. [CrossRef]

19. Elmuti, D.; Khoury, G.; Omran, O. Does entrepreneurship education have a role in developing entrepreneurial skills and ventures'effectiveness? J. Entrep. Educ. 2012, 15, 83.

20. Institute for the Future. Future Work Skills 2020. 2011. Available online: https://www.academia.edu/14823623/Future_Work_ Skills_2020 (accessed on 9 September 2021).

21. Subia, G.; Marcos, M.; Valdez, A.; Pascual, L.; Liangco, M. Cognitive Levels as Measure of Higher-Order Thinking Skills in Senior High School Mathematics of Science, Technology, Engineering and Mathematics (STEM) Graduates. Technol. Rep. Kansai Univ. 2020, 62, 1-8.

22. OECD. Future of Education and Skills 2030. 2019. Available online: https://www.oecd.org/education/2030-project/ (accessed on 19 September 2021).

23. Curaj, A.; Matei, L.; Pricopie, R.; Salmi, J.; Scott, P. The European Higher Education Area: Between Critical Reflections and Future Policies; Springer Nature: London, UK, 2015; p. 898.

24. Strom, P.S.; Strom, R.D. Teamwork skills assessment for cooperative learning. Educ. Res. Eval. 2011, 17, 233-251. [CrossRef]

25. Sancho-Thomas, P.; Fuentes-Fernández, R.; Fernández-Manjón, B. Learning teamwork skills in university programming courses. Comput. Educ. 2009, 53, 517-531. [CrossRef]

26. Loughry, M.L.; Ohland, M.W.; Woehr, D.J. Assessing teamwork skills for assurance of learning using CATME team tools. J. Mark. Educ. 2014, 36, 5-19. [CrossRef]

27. World Economic Forum. The Future of Jobs Report 2020; World Economic Forum: Geneva, Switzerland, 2020.

28. European Commission. 2018. Available online: https://ec.europa.eu/education/education-in-the-eu/digital-education-actionplan_en (accessed on 13 October 2021).

29. European Commission. 2020. Available online: https:/ / ec.europa.eu/commission/presscorner/detail/ro/IP_20_1743 (accessed on 10 September 2021).

30. Grasmane, D.; Grasmane, S. Foreign language skills for employability in the EU labour market. Eur. J. High. Educ. 2011, 1, 192-201. [CrossRef]

31. Fabo, B.; Beblavý, M.; Lenaerts, K. The importance of foreign language skills in the labour markets of Central and Eastern Europe: Assessment based on data from online job portals. Empirica 2017, 44, 487-508. [CrossRef]

32. Naros, M.S. Foreign Direct Investment and Human Capital Formation. J. Intercult. Manag. 2019, 11, 163-178. [CrossRef]

33. Nair, G.S.; Astroza, S.; Bhat, C.R.; Khoeini, S.; Pendyala, R.M. An application of a rank ordered probit modeling approach to understanding level of interest in autonomous vehicles. Transportation 2018, 45, 1623-1637. [CrossRef]

34. Bhat, C.R. The maximum approximate composite marginal likelihood (MACML) estimation of multinomial probit-based unordered response choice models. Transp. Res. Part B Methodol. 2011, 45, 923-939. [CrossRef]

35. Taylor, D. Employment preferences and salary expectations of students in science and engineering. BioScience 2007, 57, 175-185. [CrossRef]

36. Jerrim, J. Do UK higher education students overestimate their starting salary? Fisc. Stud. 2011, 32, 483-509. [CrossRef]

37. Beerepoot, N.; Lambregts, B. Competition in online job marketplaces: Towards a global labour market for outsourcing services? Glob. Netw. 2015, 15, 236-255. [CrossRef]

38. Burgess, H.; Baldwin, M.; Dalrymple, J.; Thomas, J. Developing self-assessment in social work education. Soc. Work. Educ. 1999, 18, 133-146. [CrossRef]

39. Boockmann, B.; Steffes, S. Workers, firms, or institutions: What determines job duration for male employees in Germany? ILR Rev. 2010, 64, 109-127. [CrossRef]

40. Deaconu, A.; Rașcă, L. How to Improve the Labor Market Insertion of Graduates in Romania. In Proceedings of the International Management Conference, Bucharest, Romania, 6-7 November 2014; Volume 8, pp. 794-805.

41. Eurofound. Reconciliation Measures in Times of Demographic Change; Eurofound: Dublin, Ireland, 2015.

42. Szeles, M.R.; Simionescu, M. Regional Patterns and Drivers of the EU Digital Economy. Soc. Indic. Res. 2020, 150, 95-119. [CrossRef]

43. Brancu, L.; Munteanu, V.; Gligor, D. Study on student's motivations for entrepreneurship in Romania. Procedia-Soc. Behav. Sci. 2012, 62, 223-231. [CrossRef]

44. Todea, N.; Tilea, D.M. Comparative analysis between the models for financing of education in Romania and the United Kingdom. Procedia-Soc. Behav. Sci. 2011, 15, 717-721. [CrossRef] 